\title{
Absorbance Unit per Milliliter
}

National Cancer Institute

\section{Source}

National Cancer Institute. Absorbance Unit per Milliliter. NCI Thesaurus. Code C126078.

A unit of optical density expressed as the absorbance of light transmitted through the medium on the logarithmic scale per unit of volume equal to one milliliter. 